\title{
Reagent grade yeast RNA injections and rat performance on the Hebb-Williams maze'
}

JAMES R. ISON AND PAUL TAPLIN

UNIVERSITY OF ROCHESTER

Albino rats $(\mathrm{N}=18)$ received daily yeast $\mathrm{RNA}(160 \mathrm{mg} / \mathrm{kg}$, IP) or saline injections from age 31 days to 73 days, with Hebb-Williams problems presented one per day on the last 12 days. There was no general facilitation from this manipulation but a Problems by Injection interaction $(p<.05)$ indicated that the injection led to better performance on some problems, with a suggestion $(r=+.33)$ that the degree of facilitation was related to problem difficulty. These data indicate that the injected substance does have an effect on complex problem-solving processes in distinction to some past conclusions that only general stimulation effects result.

Recent experiments (Camerson \& Solyom, 1961; Cameron et al, 1963; Brown, 1966) demonstrate that administration of yeast RNA improves performance in a variety of experimental tasks. These demonstrations have obvious relevance to theoretical concerns about the chemical microstructure of learning and memory, but it must be noted that in the infra-human work, at least, positive effects have been obtained only in shock-avoidance pole-climbing and bar pressing whereas simple discrimination learning (Wagner et al, 1966; Corson \& Enesco, 1966) fails to demonstrate facilitation. These negative findings suggest that the positive effects are attributable to non-specific activation and/or a specific effect on the topography of a shock elicited response that is facilitating for pole climbing but not running (Corson \& Enesco, 1966).

The present work was stimulated by a consideration of older research which demonstrated that the degrading effect of physiological destruction (cortical lesions) increased with increased problem difficulty (Lashley, 1929 , p. 74), which suggests that a converse positive effect of organic intervention might similarly interact with problem difficulty. The animal intelligence test devised by Hebb \& Williams (1946) contains a number of detour problems and appeared to be a useful test instrument for assessing facilitating effects of RNA.

A deliberate decision in the present work was to inject Ss as soon after weaning as possible. This was not an experimental variable in that two or more age levels were not included in the design, but it seemed that the use of young $\mathrm{Ss}$ in this preliminary exploration might maximize the success of the treatment.

Method

Subjects. The Ss were 18 male albino rats, offspring of pregnant females from Blue Spruce Farms, Altamont, New York, and weaned at 22 days of age.

Apparatus. A grey box, 30 in. $x 30$ in. $x 4$ in., was marked by red lines into 5 in. squares on the floor. Start and goal boxes, 9 in. $\times 4$ in. $\times 4$ in. were placed outside at diagonal corners. The field was covered by a sheet of $1 / 4$ in. Plexiglas and maintained in a fixed position in a heterogeneous sound attenuated room.

Procedure. Injections were begun when Ss were 31 days old and were given by two other workers who alone knew the assignment of Ss to groups. One group received daily RNA (160 mg/kg, IP, Reagent grade, Nutritional Biochemicals Corp.) and a second received equivalent volume of saline. Injections were given at about 5 p.m. throughout the experiment. After 18 days Ss were placed on a 23-hr. water deprivation schedule and pretraining trials were begun. Six arrangements of wooden barriers were selected for pretraining (not those used later) and Ss ran on one problem for 10 trials each day. The series of six problems was presented twice, until at least 9 of the 10 trials each could be completed within $60 \mathrm{sec}$. for every $\mathrm{S}$.

Experimental testing began after 31 days of injections. Problems IA to IL in Hebb \& Williams (1946) were presented in alphabetical order, one/day for 10 trials, with an intertrial interval of $15 \mathrm{sec}$. with $.2 \mathrm{cc}$ water

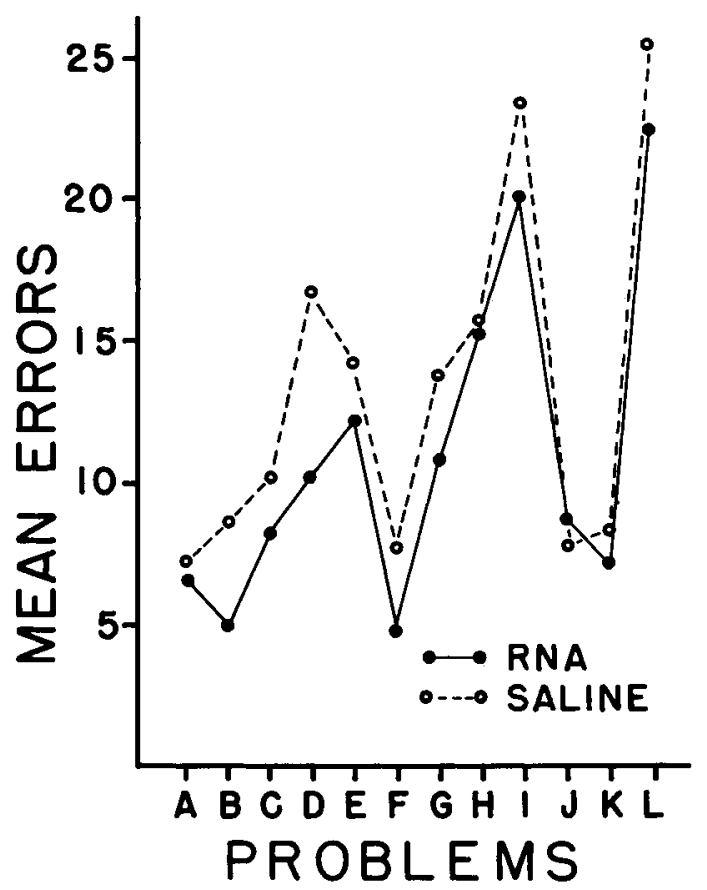

Fig. 1. Mean errors on each problem for groups receiving RNA or saline injections. 
reward. Ss were run in two squads, one from 10-12 a.m., a second from 1-3 p.m. each day. The number of entered error zones (floor squares outside the shortest path) on each trial and response time were recorded.

\section{Results}

Figure 1 depicts mean error scores for each problem for each group. The RNA injected group made fewer errors on all but one of the problems. Errors were subjected to a mixed design analysis of variance (Lindquist, 1953) with Problems (P) the within-S and Injection Condition (I) the between-S variable; this yielded a significant $P$ effect, $F=19.0, \mathrm{df}=11 / 176, \mathrm{p}<.01$, and a $P$ by $I$ interaction, $F=2.2, \mathrm{df}=11 / 176, \mathrm{p}<.05$, but no I main effect $(F<1.0)$. Separate t-tests using Lindquist's procedure (1953, p. 212) yielded a significant group difference only for Problem $D, t=1.88$, $\mathrm{df}=16 / 176$, $p<.05,1-$ tail. For a further analysis of the effects of Problems on the Injection effect a correlation (Pearson r) was calculated between the mean errors of the control group (defining problem difficulty) and the difference between the control group and the experimental group (defining facilitation). This yielded $r=+.33$.

Analyses yielded no significant differences for total time scores (790 sec. for experimental, 768 for control) nor weight changes during the total experimental period (209 $\mathrm{gm}$ for the experimental group, $228 \mathrm{gm}$ for the control group).

\section{Discussion}

The critical result was the yeast RNA did affect complex learning. The effect was not powerful, nor was it across all problems, but it does suggest a facilitory process of greater theoretical importance than simple energization or a modification of the topography of the rat's response to noxious stimuli. Further, the indication that the extent of facilitation is related to problem difficulty suggests that past failures to obtain facilitation in simple discrimination learning might be attributed to these tasks being insufficiently difficult or complex. Also to be considered is the fact that the Hebb-Williams test consists of a series of related tasks; one might speculate that the facilitation depends on the extent to which complex tasks require the utilization of previously learned responses for their solution. Whatever the final resolution of this problem, it is clear that further work is necessary on the dimensions of the tasks used in these investigations.

From a chemical standpoint it is necessary to point out, as others have done (Corson \& Enesco, 1966), that positive effects do not necessarily support speculations that ribonucleic acid plays a major role in the chemical basis of memory and learning. Yeast RNA is a conglomerate of RNA and many contaminators and with the recent evidence that exogenous RNA does not penetrate the brain (Eist \& Seal, 1965) it is likely that the contaminators or some RNA byproducts are responsible for the effect. In this connection it is interesting that selective biochemical destruction of the substances extracted from "trained brains" and injected into untrained animals, which has led sometimes to interanimal response transfer, suggests that the responsible chemical is not in fact RNA (Rosenblatt etal, 1966a, b).

\section{References}

Brown, H. Effect of ribonucleic acid (RNA) on the rate of lever pressing in rats. Psychol. Rec., 1966, 16, 173-176.

Cameron, D. E., \& Solyom, L. Effects of ribonucleic acid on memory. Geriatrics, 1961, 16, 74-81.

Cameron, D. E., Sved, S., Solyom, L., Weinrib, B., \& Barik, Effects of ribonucleic acid on memory deficit in the aged. Amer. J. Psychiat., 1963, 120, 320-325.

Cook, L., Davidson, A. N., Davis, D. J., Green, H., \& Fellows, E. J. Ribonucleic acid: effect on conditioned behavior in rats. Science, 1963, 141, 268-269.

Corson, J. A., \& Enesco, H. E. Some effects of injections of ribonucleic acid. Psychon. Sci., 1966, 5, 217-218.

Eist, H., \& Seal, U. S. The permeability of the blood-brain barrier and blood-CSF barrier to $\mathrm{C}^{14}$ tagged ribonucleic acid. Amer. $J$. Psychiat., 1965, 122, 584-586.

Hebb, D. O., \& Williams, K. A method of rating animal intelligence. J. genet. Psychol., 1946, 34, 59-65.

Lashley, K. S. Brain mechanisms and intelligence. Chicago: University of Chicago Press, 1929.

Lindquist, E. F. Design and analysis of experiments in psychology and education. Boston: Houghton Mifflin, 1953.

Rosenblatt, F., Farrow, J. T., \& Rhine, S. The transfer of learned behavior from trained to untrained rats by means of brain extracts, I. Proc. Nat. Acad. Sci., 1966, 55, 548-555.

Rosenblatt, F., Farrow, J. T., \& Rhine, S. The transfer of learned behavior from trained to untrained rats by means of brain extracts, II. Proc. Nat. Acad. Sci., 1966, 55, 787-792.

Wagner, A. R., Carder, J, B., \& Beatty, W. W. Yeast ribonucleic acid: effects on learned behavior in the rat. Psychon. Sci., $1966,4,33-34$.

\section{Note}

1. This research was supported by research grant NSF GB 4373 and was conducted in part during the junior author's tenure as an NSF undergraduate research participant. We thank David Glass and Richard Page for their assignment of Ss to groups and for the management of the injection procedures.

\section{Errafum}

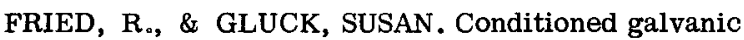
skin response in the chick embryo: Preliminary report. Psychon. Sci., 1966, 6 (7), 319-320.-Figure 1 was mismounted in photography and should have been turned counterclockwise 90 degrees. 